\title{
Pro-Angiogenesis Therapy and Aging: A Mini-Review
}

\author{
Charles T. Ambrose
}

Department of Microbiology, Immunology, and Molecular Genetics, College of Medicine, University of Kentucky, Lexington, KY, USA

\section{Keywords}

Capillary density · Lesser ailments of aging · Angiogenic growth factors - Angiogenesis hypothesis of aging ·

Pro-angiogenesis therapy

\begin{abstract}
Apart from major illnesses and chronic afflictions, the elderly experience lesser ailments, such as muscle weakness, cold intolerance, and transient memory lapses. Physical signs in the aged include wrinkled skin and the slow healing of skin abrasions. These ailments and signs are grouped together because they may be due in part to an age-linked, waning microcirculation. A reduced capillary density (CD) throughout the body of aged people and animals has been reported in over 40 papers. The reduced CD is due in turn to declining levels of angiogenic growth factors (AGFs) throughout the body during old age, as documented in 7 reports in the literature. From this perspective, old age is a deficiency state of AGFs, much like the reduced testosterone levels in elderly males. The above data on reduced CD and AGFs are the basis for the "angiogenesis hypothesis of aging", whose corollary suggests pro-angiogenesis therapy for symptoms and signs of old age. Several AGFs are now available in recombinant forms (e.g., vascular endothelial growth factor) and have been used safely in animal experiments and in short-term clinical trials.

(c) 2017 S. Karger AG, Basel
\end{abstract}

\section{KARGER}

(C) 2017 S. Karger AG, Basel

E-Mail karger@karger.com

www.karger.com/ger

\section{Introduction}

Elderly persons may experience a range of medical conditions: a fatal disease (cancer, stroke, etc.), chronic afflictions (diabetes, arthritis, atrial fibrillation, etc.), and troubling lesser ailments. The last is a collective term for 5 minor symptoms and signs of old age, which include general muscle weakness, cold intolerance, minor memory lapses, skin wrinkles, and the slow healing of bruises or abrasions in the skin [1]. The lesser ailments of aging (LAA) are the focus of this review and are grouped together here because they may have a common vascular cause and may be treatable, as next explained.

It is well recognized that atherosclerosis in arteries and arterioles leads to major illnesses - stroke, heart disease, and peripheral vascular disease. Later in life, changes occur at the terminal end of the vascular tree, where capillaries develop looping, kinking, and extensive tortuosity [2]. Not commonly appreciated is that capillaries also undergo significant regression in absolute number. Over 40 published studies have reported a reduced capillary density (CD) throughout the body of aged animals and people. These findings are discussed below with representative data being listed in Table 1 .

The development and maintenance of capillaries depend on angiogenesis (AG) - i.e., on genetically programmed levels of angiogenic growth factors (AGFs).
Prof. Charles T. Ambrose, MD

Department of Microbiology, Immunology, and Molecular Genetics College of Medicine, University of Kentucky

Lexington, KY 40536 (USA)

E-Mail cambros@uky.edu 
Table 1. Capillary density

\begin{tabular}{|c|c|c|}
\hline First author, year [ref.] & Adult & Aged (or AD) \\
\hline \multicolumn{3}{|l|}{ Brain } \\
\hline \multicolumn{3}{|l|}{ Craigie, 1925 [6] } \\
\hline Rats - regio insularis & 856 (5 months) & 638 (13 months) \\
\hline \multicolumn{3}{|l|}{ Buchweitz-Milton, 1987 [7] } \\
\hline Rats - cortex & 830 (8-10 months) & 577 (21-33 months) \\
\hline Rats -6 brain areas & 837 (8-10 months) & 592 (21-33 months) \\
\hline \multicolumn{3}{|l|}{ Mann, $1986[8]$} \\
\hline People - frontal cortex & 966 (26-58 years) & 784 (76-96 years) \\
\hline \multicolumn{3}{|c|}{ Fischer, 1990 [9] - normal vs. AD subjects } \\
\hline Prefrontal cortex & $94.6(23-90$ years $)$ & $75.4(\mathrm{AD}, 76-92$ years $)$ \\
\hline Basal forebrain & 86.8 (23-90 years) & $42.7(\mathrm{AD}, 76-92$ years $)$ \\
\hline Hippocampus & 82.0 ( $23-90$ years $)$ & $50.2(\mathrm{AD}, 76-92$ years $)$ \\
\hline \multicolumn{3}{|l|}{ Muscle } \\
\hline \multicolumn{3}{|l|}{ Rivard, 1999 [10] } \\
\hline Mice & 710 (12 weeks) & 350 (2 years) \\
\hline Rabbits & 170 (6-8 months) & 130 ( $4-5$ years $)$ \\
\hline \multicolumn{3}{|l|}{ Coggan, 1992 [11] } \\
\hline Male subjects & 308 (av. 24 years) & 228 (av. 64 years) \\
\hline Female subjects & 338 (av. 24 years) & 248 (av. 64 years) \\
\hline \multicolumn{3}{|l|}{ Skin } \\
\hline \multicolumn{3}{|l|}{ Helmbold, 2006 [12] } \\
\hline Human chest area & $4.4(15-20,39-40$ years $)$ & 2.3 (>70 years) \\
\hline \multicolumn{3}{|l|}{ Vollmar, 2000 [13] } \\
\hline Hairless rat ear & 77.6 (30 weeks) & 37.5 (78 weeks) \\
\hline \multicolumn{3}{|l|}{ Výbohová, 2012 [14] } \\
\hline Human chest area, \%/unit area & $1.42(31-50$ years $)$ & $0.47(81-89$ years $)$ \\
\hline \multicolumn{3}{|l|}{ Larynx } \\
\hline \multicolumn{3}{|l|}{ Russell, 2008 [15] } \\
\hline Rat thyroarytenoid muscle & 17.0 (9 months) & 9.35 (28-30 months) \\
\hline \multicolumn{3}{|l|}{ Colon } \\
\hline \multicolumn{3}{|l|}{ Gabella 2001 [16] } \\
\hline Guinea pig colon muscle, CD & 9/unit area (ns) & 5/unit area (ns) \\
\hline \multicolumn{3}{|l|}{ Kidney } \\
\hline \multicolumn{3}{|l|}{ Stefanska, 2015 [17] } \\
\hline Mouse kidney cortex, CD & 1.40 (3 months) & 0.93 (27 months) \\
\hline Mouse kidney medulla, CD & 1.52 (3 months) & 1.04 (27 months) \\
\hline \multicolumn{3}{|l|}{ Urbieta-Caceres, 2012 [18] } \\
\hline Mouse renal cortex, CD & 30 (6 months) & 17 (18-22 months) \\
\hline \multicolumn{3}{|l|}{ Kang, $2001[19]$} \\
\hline Rat kidney, peritubular, CD & $11.3 \%$ (3 months) & $5.4 \%$ (24 months) \\
\hline
\end{tabular}

The units of measurement for the above data differ among the studies and are omitted to keep these tables less cluttered. AD, Alzheimer disease; CD, capillary density; ns, precise ages not stated; av., average.

During early growth and maturation of the body, the development and function of various organ systems involve rising levels of AGFs and an expanding microcirculation. However, during old age, people and animals show declining levels of such factors in various organ systems, paralleling the reduced CD. Data from 7 such studies are discussed later and are presented in Table 2. Thus, old age represents a deficiency condition for AG factors, much like hormone levels that are decreased in the elderly. 
Table 2. Levels of angiogenic factors

\begin{tabular}{|c|c|c|}
\hline First author, year [ref.] & Adult & Aged (also AD) \\
\hline \multicolumn{3}{|l|}{ Brain } \\
\hline \multicolumn{3}{|l|}{ Viboolvorakul, 2014 [27] } \\
\hline Rats - parietal cortex, VEGF & 32.3 (4-6 months) & 20.5 (23-24 months) \\
\hline \multicolumn{3}{|l|}{ Muscle } \\
\hline \multicolumn{3}{|l|}{ Wagatsuma, 2006 [28] } \\
\hline Mice - VEGF & 1.0 (av. 2.5 months) & 0.7 (22 months) \\
\hline \multicolumn{3}{|l|}{ Ryan, 2006 [29] } \\
\hline Men - VEGF & 1.05 (19-25 years) & $0.55(60-72$ years $)$ \\
\hline Men - mRNA VEGF & $1.0(19-25$ years $)$ & $0.4(60-72$ years $)$ \\
\hline Men exercise - mRNA VEGF & 3.4 (19-25 years) & $1.8(60-72$ years $)$ \\
\hline \multicolumn{3}{|l|}{ Kidney } \\
\hline \multicolumn{3}{|l|}{ Kang, 2001 [19] } \\
\hline Rat, kidney medulla, VEGF & $39.3 \%$ (3 months) & $19.2 \%$ (24 months) \\
\hline \multicolumn{3}{|l|}{ Vein Wall } \\
\hline \multicolumn{3}{|l|}{ Drubaix, 1998 [30] } \\
\hline Human - bFGF & $180(20-24$ years $)$ & 50 (61-82 years) \\
\hline \multicolumn{3}{|l|}{ Mononuclear cells } \\
\hline \multicolumn{3}{|l|}{ Solerta, $2002[31]$} \\
\hline Human - VEGF & 296 (av. 32.2 years) & 137 (av. 77 years) \\
\hline Human - VEGF & 296 (av. 32.2 years) & $125(\mathrm{AD}$, av. 76.5 years $)$ \\
\hline \multicolumn{3}{|l|}{ Macrophage, activated by IFN- $\gamma$} \\
\hline \multicolumn{3}{|l|}{ Swift, 1999 [32] } \\
\hline Mice - secreted VEGF, pg/mL & 198.9 (2-3 months) & 124.0 (22-24 months) \\
\hline
\end{tabular}

The idea that the lesser ailments may be due in part to age-associated diminished CD/AGFs is termed "the angiogenesis hypothesis of aging." Its corollary suggests that treatment with exogenous angiogenic factors should restore reduced CD in areas experimentally depleted of capillaries and may improve function in areas of naturally impaired microcirculation. Recombinant angiogenic factors have been shown to induce new capillary formation in ischemic and normoxic tissues within days, as observed in numerous animal studies mentioned later. Thus, in theory, pro-AG therapy may ease the LAA after they have appeared or delay their development. This is in contrast to the pathology in the larger blood vessels, where fatty plaques and cholesterol deposits cannot be readily eliminated once acquired but only prevented in the decades before old age by avoiding risk factors - i.e., obesity, diabetes, hypertension, etc. [3].

Because of the biographical constraints of this journal, this paper has been limited to presenting studies with key data in support of the AG hypothesis and in advancing its therapeutic corollary. Not covered here are detailed discussions of specific AGFs, therapeutic regimens with recombinant forms, and other potential treatments involving gene transfer or progenitor cells. These particular matters were treated in prior papers and in numerous primary sources cited in them $[4,5]$.

\section{Reduced CD in Old Age}

The age-linked reduction of capillaries in the brain and muscle was the main focus of several earlier reviews [4, 5]. Representative data from both organ systems are presented below. Since the publication of these papers, additional examples of a reduced CD elsewhere in the body have been identified in other research reports and are included later and in Table 1. 


\section{Brain}

An age-linked reduction in capillaries was first described in the brains of older rats by Craigie [6] in the 1920s. For example, he found CD values of 856 and $638 \mu$ in the regio insularis of 2- and 13-month-old rats, respectively. Here, CD values are shown as "data pairs" (e.g., 856 vs. $638 \mu$ ), indicating average values found in adults versus those in the aged. In Table 1, 7 representative data pairs from 4 reports [6-9] are listed, showing reduced cerebral $\mathrm{CD}$ in old rats, aged people, and subjects with $\mathrm{Al}$ zheimer disease (AD).

\section{Muscle}

The reduction of $\mathrm{CD}$ with age has also been reported in skeletal muscles. For example, Rivard et al. [10] examined the $\mathrm{CD}$ in muscles of mice and found an average value of $710 \mathrm{~mm}^{3}$ in 12 -week-old mice but only $350 \mathrm{~mm}^{3}$ in 2-year-old mice. In the middle of Table 1 are listed four representative data pairs from the muscles of mice, rabbits, and people $[10,11]$.

\section{Other Organs}

A similar reduction in the $\mathrm{CD}$ with age has been noted in other areas of the body - skin, larynx, colon, kidneys, and lungs. For example, Helmbold et al. [12] examined human skin and reported the average CD of $4.4 \mathrm{n} / \mathrm{HPF}$ for those aged 39-40 years and only $2.3 \mathrm{n} / \mathrm{HPF}$ for those $>70$. In the lower half of Table 1 , representative data from 8 reports on various parts of the body are listed [12-19].

\section{Lungs}

Among the LAA, senile exertional dyspnea could be included. While exertional dyspnea occurs at all ages and is generally due to cardiac insufficiency or obstructive lung disease, during old age, an additional cause may be a lowered alveolar gas exchange due to reduced alveolar CD. Butler and Kleinerman [20] measured pulmonary $\mathrm{CD}$ and found a smaller $\mathrm{CD}$ to alveolar diameter ratio $(\mathrm{CD} / \mathrm{AD})$ in the lungs of older persons. From Table 1 of their paper, I calculated that the $\mathrm{CD} / \mathrm{AD}$ ratio averaged 0.47 for 15 measurements in 5 adults aged 17-31 years and 0.36 for a similar set of data from older subjects aged 49-57. Georges et al. [21] observed a decreased pulmonary capillary blood volume in subjects after 50 years of age. Thurlbeck and Angus [22] interpreted a reduction in alveolar parenchymal tissue in aged persons as reflecting a loss of pulmonary capillaries because of a widespread, age-linked reduction in CD.

\section{Summary}

Little mention has been made in clinical papers that a reduced $\mathrm{CD}$ occurs during aging throughout the body, but, as noted above, this change has been reported in the research literature for 7 different organ systems. Evidence of this reduction is the 20 representative data pairs from 14 reports presented here in Table 1 . To date, a total of the 64 data pairs from 40 reports have been found, as listed above and in 3 previous papers $[1,4,5]$. The widespread reduced microcirculation is associated chronologically with the development of the symptoms and signs of old age in both higher animals and people. It seems logical to consider this reduction as one possible cause of the LAA.

\section{Declining AG in Old Age}

The existence of a vasculogenic factor was first postulated in 1948 by Michaelson (1903-1983) [23], a British ophthalmologist, who studied capillary growth in the developing retina of cats and people. In 1971, Folkman (1933-2008) and Klagsbrun [24] isolated an angiogenic factor (later termed angiogenin), which promoted the growth of solid tumors by developing a new capillary network nourishing them. Transient local AG also occurs during the ovarian cycle and pregnancy and in areas of wound healing and other injuries involving ischemia; e.g., cerebral infarcts.

To my knowledge, there has been no report that has measured the general development of the microcirculation throughout life relative to levels of angiogenic factors. However, based on Craigie's study [6; Fig. 4] of CD in rat brains from birth to late maturity, levels of these AG factors must follow a chronological course similar to that of $\mathrm{CD}$ - i.e., they rise sharply during early life, peak with the full development of the capillary beds in organ systems, remain at a plateau level during maturity, and begin to decline in old age. As the reduced CD during aging discussed in the previous section, waning levels of angiogenic factors in later life have been documented by many investigators in numerous organ systems (see below). As noted earlier, this age-linked decline seems analogous to the falling values of testosterone in older males and the declining levels of other hormones with age. An association between the changes in hormone level in the aged and the age-linked decline in AGFs was discussed in a prior paper [5].

AG involves various vascular growth factors, some working in concert with others [25]. Three well-studied
396

Gerontology 2017;63:393-400

DOI: 10.1159/000477402
Ambrose 
Table 3. Treatment with an angiogenic growth factor

\begin{tabular}{|c|c|c|c|c|}
\hline \multicolumn{5}{|l|}{ Brain } \\
\hline Rosenstein, 1998 [36] & rat & VEGF & $\begin{array}{l}\text { 3-mm depth near coronal/ } \\
\text { sagittal sutures }\end{array}$ & $\uparrow$ vascular tissue in infusion site \\
\hline Puumala, 1990 [37] & rat & FGF-2/b & left lateral ventricle & $\begin{array}{l}\uparrow \mathrm{CD} \text { in left perilateral ventricular } \\
\text { cortex }\end{array}$ \\
\hline Thau-Zuchman, 2010 [38] & mice & VEGF & lateral ventricle & $\uparrow$ angiogenesis in brain area traumatized \\
\hline Wang, 2006 [39] & rat & VEGF & intraventricular doses & $\begin{array}{l}\uparrow \text { motor/memory function after focal } \\
\text { cerebral ischemia }\end{array}$ \\
\hline \multicolumn{5}{|l|}{ Ischemic limb model } \\
\hline Rivard, 1999 [10] & rabbits, mice & VEGF, i.v. bolus $\times 1$ & $\rightarrow \uparrow \mathrm{CD}$ & \\
\hline Baffour, 1992 [40] & rabbits & rh bFGF, i.m. qd, $\times 2$ weeks & $\rightarrow \uparrow \mathrm{CD}$ & \\
\hline Yang, 1996 [41] & rats & bFGF, subQ pump $\times 14$ days & $\rightarrow \uparrow \mathrm{CD}$ & \\
\hline
\end{tabular}

such agents are vascular endothelial growth factor (VEGF), fibroblast growth factor (FGF-1 and -2), and angiopoietin. These and other growth factors have been extensively reviewed elsewhere [26]. The aspect of AG relevant for this paper is the finding that these factors in the body decline during old age.

\section{Organ Systems Affected}

While there are no published reports on levels of angiogenic factors in the aging human brain, Viboolvorakul and Patumraj [27] found reduced VEGF protein in the parietal cortex of aged rats; e.g., values of $32.3 \mathrm{pg} / \mathrm{mg}$ protein in 4-5-month-old rats versus $20.5 \mathrm{pg} / \mathrm{mg}$ protein in 23-24-month-old rats. Reduced levels of VEGF protein and/or messenger RNA VEGF have been recorded in other organ systems of aged mice, rats, or humans - i.e., in the muscles, kidney medulla, vein wall, mononuclear cells, and macrophages. In Table 2, 10 representative data pairs showing diminished levels of angiogenic factors in 6 organs or cell systems of aged people and animals are listed. [19, 27-32]. A general decline in AG throughout the human body would account for the reduced CD observed in many organ systems of the elderly. How such a decline may lead to aged-looking skin and long-lasting bruises is explained below.

\section{Aging Skin}

The skin on the face, upper arms, and dorsum of the hands of elderly persons becomes loose and wrinkled due to loss of subcutaneous fat. Throughout adulthood, adipose tissue can expand or regress, as many weight watchers know. Body fat is highly vascularized with an extensive capillary network surrounding each adipocyte.

Pro-Angiogenesis and Aging
Rupnick et al. [33] reported that AG inhibitors "significantly decreased" adipose tissue in mice and concluded that adipose tissue mass is "regulated by its vasculature" - i.e., via local AG. Thus, the age-linked decline in AG in the elderly may cause depletion of subcutaneous fat notably in the hand dorsum, leading to the loss of a filling/ smoothing effect there. Three data pairs showing a reduced CD in aged skin (likely also in its subcutaneous fat) are listed in Table 1. Visceral/abdominal fat is less responsive to angiogenic control, which may account for a fat belly in persons with wrinkles elsewhere [34].

\section{Slow-Healing Skin Lesions}

Bruises and small abrasions on the skin are more conspicuous in elderly than in younger subjects, perhaps because these injuries are slower to heal in the former. Various conditions account for this greater incidence, including increased capillary fragility with age. In old mice and rats, slow healing has also been ascribed to a "decrease in capillary growth" and "delayed AG" $[32,35]$.

\section{Pro-AG by AGFs}

Support for the therapeutic corollary of the AG hypothesis comes from studies showing that recombinant AGFs improve the local microcirculation or function not only in ischemic areas but also in normoxic organs.

\section{Animal Brain Studies}

Examples of animal brain studies are listed in Table 3 [36-39]. Using an osmotic mini pump, Rosenstein et al. [36] infused recombinant VEGF to a 3-mm depth near

Gerontology 2017;63:393-400 397 
the coronal/sagittal sutures in normal adult rats and observed "remarkable neovascularization" in the involved cortical area. Another group injected basic fibroblastic growth factor into the lateral ventricle of normal rats and reported increased AG in the adjacent brain cortex [37]. Thau-Zuchman et al. [38] administered VEGF into the later ventricle of mice following traumatized brain injury and noted increased AG in the affected area. Improved motor function and memory followed intraventricular doses of VEGF in mice and rats subject to focal cerebral ischemia [39].

\section{Animal Muscle Studies}

An experimental model for inducing AG in muscles has involved occluding the femoral artery of a hind limb of rabbits, rats, or mice to render it ischemic. Different AGFs (VEGF, basic FGF) were injected by various routes and produced an increased local CD. Three such reports are listed in Table 3 and present the details of therapy [10, $40,41]$.

\section{Clinical Muscle Trials}

Subjects with limited walking tolerance (ca. $5 \mathrm{~min}$ ) due to intermittent claudication were given bilateral femoral artery infusions of FGF-2 according to various schedules. In some groups, the day-90 walking time was increased by $1-2 \mathrm{~min}$ beyond the baseline level [42]. The maximum tolerated dose was $30 \mathrm{~g} / \mathrm{kg}$; a higher level induced acute hypotension. Cautions concerning pro-AG therapy were discussed elsewhere [4].

\section{Clinical Myocardium Trials}

Patients with impaired cardiac function have received 1 or several injections into the myocardium of recombinant proteins of various AGFs [43]. While initial reports suggested favorable results, later evaluations showed equivocal long-term clinical benefit in double-blind, randomized placebo-control trials [43]. However, these studies demonstrated the safety of the recombinant factors. A table in the paper by Annex and Simons [43] lists the results of 9 clinical trials involving angiogenic protein therapy in subjects with myocardial insufficiency.

\section{Clinical Brain Study}

Harry S. Goldsmith performed an extraordinary surgical procedure, which suggested that raising the cerebral level of AGFs would benefit patients with AD. The rationale for his work rested on the extremely high levels of VEGF protein in rat omentum - e.g., $884 \mathrm{pg} / \mathrm{mg}$ compared to $8 \mathrm{pg} / \mathrm{mg}$ (sic) in the brain [44]. Goldsmith et al.
[45] "stretched" an omental pedicle flap from the transverse colon of human subjects with $\mathrm{AD}$ onto the surface of their brains. This was done by pulling an omentum flap from the colon through a subcutaneous pathway up the anterior abdominal wall, chest, and neck to the base of the skull. After being brought through openings in the skull, the dura mater, and arachnoid membrane, the end of the omentum flap was laid directly on the parietal-temporal area of 1 hemisphere - all the while maintaining its original circulation. Some AD subjects subsequently exhibited marked cognitive improvement [45]. Post-mortem examination of a dozen or so $\mathrm{AD}$ cases given such flapgrafts showed that collateral circulation had been established in the area under the pedicle and had also increased the microcirculation in zones apart from the omental placement, such as the occipital area and contralateral cerebral hemisphere [45]. These findings indicate that local AG was induced by the growth factors released into the brain from the viable flap.

\section{Advocates of Pro-AG for Maintaining the Microcirculation}

Pro-AG treatment of the elderly has inferential support from the comments of investigators regarding the importance of AG in maintaining the microvascular system. In 1986, Bär et al. [46; p 223] wrote that the capillary plexus "needs a continuous action of an angiogenic stimulus." In 1992, Ferrara et al. [47; p 28] concluded that the "presence of growth factor[s] may be required to maintain the differentiated state of those vessels." In 2005, Carmeliet [48; p 936] stated: "Threshold levels of VEGF (are needed) for the survival and maintenance of quiescent vessels in healthy organs."

In 1998, Baumgartner and Isner [49; p 201] prefaced an article as follows: "AGFs constitute a potentially novel form of therapy for patients with ischemic vascular diseases." In 2011, Carmeliet and Jain [26; p 298] concluded that "The revascularization of ischaemic tissues would benefit millions, but therapeutic AG is an unmet medical need."

\section{Clinical Assessment}

Evaluating the clinical benefit of any pro-AG therapy in the elderly would rest mainly on subjective self-appraisals, such as sensing improved strength or noting "a sharper memory" - fewer instances of lapsed recall of
398

Gerontology 2017;63:393-400

DOI: $10.1159 / 000477402$
Ambrose 
names or facts. Currently, the only objective measurement of an increased CD would be histologic studies on muscle biopsies or at autopsy. CD visualized under the fingernails, in the forearm skin, or in the conjunctiva has as yet insufficient background data on which to evaluate any small improvement during a therapeutic trial. Simons [25] remarked on the absence of any useful biomarkers for $\mathrm{CD}$ in subjects in a clinical trial and cautioned about a placebo effect.

\section{Conclusions}

Countless theories have been advanced to explain aging in people but none has led to a widely accepted treatment based on reversing an underlying cause $[1,50]$. Physiological aging is commonly assumed to be due to various causes. Indeed, if aging is the result of several enfeebling influences, then lessening any one might ease its symptoms and signs. Again, there is abundant evidence in the literature that a reduced $\mathrm{CD}$ and a waning AG occur during old age. It seems likely that these linked changes influence the physiological state of the aged body - accounting for its fading functions and possibly for the lesser ailments. A reduced cerebral CD may contribute to the more profound cognitive problems of old age; e.g., $\mathrm{AD}$.
The animal studies described above establish that exogenous AGFs generate new capillaries. While numerous investigators have administered recombinant AGFs to relieve specific conditions of ischemia in the human body, to my knowledge, no gerontologist has proposed pro-AG therapy for moderating or delaying the widespread reduced microcirculation occurring during old age. Therapeutic pro-AG seems a tenable consideration for the lesser ailments of the elderly. The 30 data pairs in Tables 1 and 2 bring to mind George Orwell's [51] admonition "To see what is in front of one's nose needs a constant struggle."

\section{Acknowledgements}

The author gratefully acknowledges the invaluable assistance of Mrs. Amanda Williams, Medical Center Library, University of Kentucky, and the continued support of I.S. Tray II.

\section{Disclosure Statement}

The author declares that he has no financial interests in any commercial endeavor related to the subject of this paper.

\section{References}

1 Ambrose CT: The role of capillaries in the lesser ailments of old age and in Alzheimer's disease and vascular dementia: the potential of pro-therapeutic angiogenesis. J Alzheimer's Dis 2016;54:31-43.

2 Kalaria RN, Kroon SN: Expression of leukocyte antigen CD34 by brain capillaries in Alzheimer's disease and neurologically normal subjects. Acta Neuropathol 1992;84:606612.

3 de la Torre JC: Vascular risk factor detection and control may prevent Alzheimer's disease. Ageing Res Rev 2010;9:218-225.

4 Ambrose CT: A therapeutic approach for senile dementias: Neuroangiogenesis. J Alzheimer's Dis 2015A;43:1-17.

5 Ambrose CT: Muscle weakness during aging: a deficiency state involving declining angiogenesis. Ageing Res Rev 2015B;23:139-153.

6 Craigie EH: Postnatal changes in vascularity in the cerebral cortex of the male albino rat. J Comp Neurol 1925;39:301-324.

7 Buchweitz-Milton E, Weiss HR: Perfused capillary morphometry in the senescent brain. Neurobiol Aging 1987;8:271-276.

Pro-Angiogenesis and Aging
8 Mann DM, Eaves NR, Marcyniuk B, Yates PO: Quantitative changes in cerebral cortical microvasculature in ageing and dementia. Neurobiol Aging 1986;7:321-330.

9 Fischer VW, Siddiqi A, Yusufaly Y: Altered angioarchitecture in selected areas of brains with Alzheimer's disease. Acta Neuropath 1990;79:672-679.

10 Rivard A, Fabre J-E, Silver M, Chen D, et al: Age-dependent impairment of angiogenesis. Circulation 1999;99:111-120.

11 Coggan AR, Spina RJ, King DS, Rogers MA, Brown M, Nemeth PM, Holloszy JO: Histochemical and enzymatic comparison of the gastrocnemius muscle of young and elderly men and women. J Gerontol 1992;47:B71-B76.

12 Helmbold P, Lautenschläger C, Marsch WC, Navak RC: Detection of a physiological juvenile phase and the central role of pericytes in human dermal microvascular aging. J Invest Dermatol 2006;126:1419-1421.

13 Vollmar B, Morgenthaler M, Amon M, Menger MD: Skin microvascular adaptations during maturation and aging of hairless mice. Am J Physiol Heart Circ Physiol 2000; 279:H1591-H1599.
14 Výbohová V, Mellová Y, Adamicová K, Adamcov M, Hešková G: Quantitative changes of the capillary bed in aging human skin. Histol Histopathol 2012;27:961-967.

15 Russell JA, Nagai H, Connor NP: Effect of aging on blood flow in rat larynx. Laryngoscope 2008;118:559-563.

16 Gabella G: Development and ageing of intestinal musculature and nerves: the guinea-pig taenia coli. J Neurophysiol 2001;30:733-766.

17 Stefanska A, Eng D, Kaverina N, Duffield JS, Pippin JW, Rabinovitch P, Shankland SJ: Interstitial pericyte decrease in aged mouse kidneys. Aging 2015;7:370-381.

18 Urbieta-Caceres VH, Syed FA, Lin J, Zhu X-Y, Jordan KL, Bell CC, Bentley MD, Lerman A, Khosla S, Lerman LO: Age-dependent renal cortical microvascular loss in female mice. Am J Physiol Endocrinol Metab 2012; 301:E979-E986.

19 Kang D-H, Joly AH, OH SW, Hugo C, Kerjaschki D, Gordon KL, Mazzali M: Impaired angiogenesis in the aging kidney: vascular endothelial growth factor and thrombospondin-1 in renal disease. Am J Kidney Dis 2001; 37:601-611. 
20 Butler C, Kleinerman J: Capillary density: alveolar diameter, a morphometric approach to ventilation and perfusion. Am Rev Resp Dis 1970;102:886-894.

21 Georges R, Saumon G, Loiseau A: The relationship of age to pulmonary membrane conductance and capillary blood volume. Am Rev Respir Dis 1978;117:1069-1078.

22 Thurlbeck WM, Angus GE: Growth and aging of the normal human lung. Chest 1975;67: $3 \mathrm{~S}-6 \mathrm{~S}$.

23 Michaelson IC: The mode of development of the vascular system of the retina, with some observations on its significance for certain retinal diseases. Trans Ophthalmol Soc UK 1948;68:137-180.

24 Folkman J, Klagsbrun M: Angiogenic factors. Science 1987;235:442-447.

25 Simons M: Angiogenesis - where do we stand now? Circulation 2005;111:1556-1566.

26 Carmeliet P, Jain RK: Molecular mechanisms and clinical applications of angiogenesis. Nature 2011;473:298-307.

27 Viboolvorakul S, Patumraj S: Exercise training could improve age-related changes in cerebral blood flow and capillary vascularity through the upregulation of VEGF and eNOS. Biomed Res Int 2014;2014:1-12.

28 Wagatsuma A: Effect of aging on expression of angiogenesis-related factors in mouse skeletal muscle. Expl Gerontology 2006;41:49-54.

29 Ryan NA, Zwetsloot KA, Westerkamp LM, Hickner RC, Pofahl WE, Gavin TP: Lower skeletal muscle capillarization and VEGF expression in aged vs. young men. J Appl Physiol 2006;100:178-185.

30 Drubaix I, Giakoumakis A, Robert L, Robert AM: Preliminary data on the age-dependent decrease in basic fibroblast growth factor and platelet-derived growth factor in the human vein wall and in their influence on cell proliferation. Gerontology 1998;44:9-14.

31 Solerta SB, Fioravantil M: Downregulation of vascular endothelial growth factor generation from immune cells in Alzheimer's disease. Neurobiol Aging 2002;23(suppl 1):S532.
32 Swift ME, Kleinman HK, DiPietro LA: Impaired wound repair and delayed angiogenesis in aged mice. Lab Invest 1999;79:14791999.

33 Rupnick MA, Panigrahy D, Zhang C-Y, Dallabrida SM, Lowell BB, Langer R, Folkman MJ: Adipose tissue mass can be regulated through the vasculature. Proc Natl Acad Sci USA 2002;99:10730-10735.

34 Gealekman O, Guseva N, Hartigan C, Apotheker S, Gorgoglione M, et al: Depot-specific differences and insufficient subcutaneous adipose tissue angiogenesis in human obesity. Circulation 2011;123:186-194.

35 Yamaura H, Matsuzawa T: Decrease in capillary growth during aging. Exp Gerontol 1980; 15:145-150.

36 Rosenstein JM, Mani N, Silverman WF, Krum JM: Patterns of brain angiogenesis after vascular endothelial growth factor administration in vitro and in vivo. Proc Natl Acad Sci USA 1998;95:7086-7091.

37 Puumala M, Anderson RE, Meyer FB: Intraventricular infusion of HBGF-2 promotes cerebral angiogenesis in Wistar rat. Brain Res 1990;534:283-286.

38 Thau-Zuchman O, Shohami E, Alexandrovich AG, Leker RR: Vascular endothelial growth factor increases neurogenesis after traumatic brain injury. J Cerebral Blood Flow Metab 2010;30:1008-1016.

39 Wang Y, Galvan V, Gorostiza O, Ataie M, Jim $\mathrm{K}$, Greenberg DA: Vascular endothelial growth factor improves recovery of sensorimotor and cognitive deficits after focal cerebral ischemia in the rat. Brain Res 2006;1115: 186-193.

40 Baffour R, Berman J, Garb JL, Rhee SW, Kaufman AJ, Friedmann P: Enhanced angiogenesis and growth of collaterals by in vivo administration of recombinant basic fibroblast growth factor in a rabbit model of acute lower limb ischemia: dose-response effect of basic fibroblast growth factor. J Vasc Surg 1992;1:181-191.
41 Yang HT, Deschenes MR, Ogilvie RW, Terjung RL: Basic fibroblast growth factor increases collateral blood flow in rats with femoral arterial ligation. Circulation Res 1996;79: 62-69.

42 Lederman RJ, Mendelsohn FO, Anderson RD, Saucedo JF, Tenaglia AN, Hermiller JB, Hillegass WB, Rocha-Singh K, Moon TE, Whitehouse MJ, Annex BH: Therapeutic angiogenesis with recombinant fibroblast growth factor-2 for intermittent claudication (the TRAFFIC study): a randomized trial. Lancet 2002;359:2053-2058.

43 Annex BH, Simons M: Growth factor-induced therapeutic angiogenesis in the heart: protein therapy. Cardiovascular Res 2005;65: 649-655.

44 Zhang Q-X, Magovern CJ, Mazck CA, Budenbender KT, Ko W, Rosengart TK: Vascular endothelial growth factor in omentum: mechanism of the omentum-mediated angiogenesis. J Surg Res 1997;67:147-154.

45 Goldsmith HS, Bacciu P, Cossu M, Pau A, Rodriguez G, Rosadini G, Ruju P, Viale ES, Turtas SW, Viale GL: Regional cerebral blood flow after omental transposition to the ischaemic brain in man. A five year follow-up study. Acta Neurochir (Wien) 1990;106:145152.

46 Bär T, Miodonski A, Budi Santoso AW: Postnatal development of the vascular pattern in the rat telencephalicpia-arachnoid. Anat Embryol (Berl) 1986;174:215-223.

47 Ferrara N, Houck K, Jakeman L, Leung DW: Molecular and biological properties of the vascular endothelial growth factor family of proteins. Endocrine Rev 1992;13:18-32.

48 Carmeliet P: Angiogenesis in life, disease and medicine. Nature 2005;438:932-936.

49 Baumgartner I, Isner JM: Stimulation of peripheral angiogenesis by vascular endothelial growth factor (VEGF). VASA 1998;27:201206.

50 Weinert BT, Timiras PS: Theories of aging. J Appl Physiol 2003;95:1706-1716.

51 Orwell G: In front of your nose. London's Tribune, March 22, 1946. 